\title{
Estado do conhecimento sobre o formador de professores de Matemática no Brasil
}

\author{
State of knowledge about the Mathematics teacher educator in Brazil \\ Flávia Cristina Figueiredo Coura ${ }^{1}$ \\ Cármen Lúcia Brancaglion Passos ${ }^{2}$
}

\begin{abstract}
Resumo
Este estudo tem o objetivo de descrever e sistematizar o conhecimento produzido nas pesquisas defendidas de 2001 a 2012 que trazem resultados sobre o formador de professores de Matemática e foram desenvolvidas em programas brasileiros de pós-graduação stricto sensu das áreas de Educação e Ensino. A partir da leitura integral do texto das 30 investigações identificadas, foi feita uma análise qualitativa, que possibilitou agrupar esses estudos em duas temáticas. Os resultados indicam que as concepções e as práticas dos docentes da universidade que atuam na Licenciatura em Matemática têm implicações na formação dos futuros professores e que os saberes são constituídos e constitutivos da prática docente do formador, pois dominá-los, integrá-los e mobilizálos são condições para que essa formação ocorra. Essas pesquisas não discriminaram os saberes específicos do formador, necessários à sua atividade profissional, nem indicaram em que medida se diferenciam dos saberes do professor que ele forma.
\end{abstract}

Palavras-chave: estado do conhecimento; formador de professores de Matemática; formação de professores de Matemática.

\begin{abstract}
This study aims to describe and systematize the knowledge produced in the researches from 2001 to 2012 that bring results on the Mathematics teacher educator and were developed in Brazilian postgraduate programs in the areas of Education and Teaching. From the full reading of the text of the 30 investigations identified, a qualitative analysis was made, which made it possible to group these studies into two themes. The results indicate that the conceptions and practices of university teachers working in the Mathematics Degree have implications for the education teaching of future Mathematics teachers and that knowledge is constituted and constitutive of the teacher's teaching practice, because to dominate them, to integrate them and to mobilize them would be conditions to realize them. These researches do not discriminate the specific knowledges of the teacher educator, necessary for his professional activity, or to what extent they differ from the knowledge of the teacher that he forms.
\end{abstract}

Keywords: knowledge state; teacher of Mathematics teachers; education teachers in Mathematics.

\footnotetext{
${ }^{1}$ Doutoranda em Educação pela Universidade Federal de São Carlos, Professora da Universidade Federal de São João del Rey, Brasil. E-mail: flaviacoura@ufsj.edu.br

${ }^{2}$ Doutora em Educação pela Universidade Estadual de Campinas, Professora da Universidade Federal de São Carlos, Brasil. Email: carmen@ufscar.br
}

Zetetiké, Campinas, SP, v.25, n1, jan./abr.2017, p.7-26 


\section{Introdução}

Este estudo ${ }^{3}$ tem o objetivo de descrever e sistematizar as pesquisas que trazem resultados sobre o formador de professores de Matemática, produzidas em programas brasileiros de pós-graduação stricto sensu das áreas de Educação e Ensino e defendidas de 2001 a 2012. Para tanto, se fundamenta nos dados produzidos no âmbito do projeto "Mapeamento e estado da arte da pesquisa brasileira sobre o professor que ensina Matemática"4, que contou com 858 dissertações e teses em seu escopo, dentre as quais identificamos 30 que geraram resultados relativos a concepções, práticas ou formação do docente que atua na Licenciatura em Matemática. Esses 30 estudos constituem o corpus de análise deste artigo.

A fim de estabelecer um estado do conhecimento ${ }^{5}$ das pesquisas sobre o formador de professores de Matemática, apresentaremos a seguir os pressupostos que nos orientam e posteriormente relataremos o processo pelo qual identificamos e analisamos tais pesquisas. Procuramos caracterizá-las por meio de um panorama das condições de produção e de alguns dos aspectos metodológicos relacionados ao processo investigativo, na parte dedicada às tendências das pesquisas. Para sistematizar o conhecimento sobre o formador de professores de Matemática, focalizamos os resultados dos estudos selecionados, que foram organizados em duas categorias de análise. Ao final, teceremos algumas considerações sobre tendências, mudanças de ênfase e orientações perceptíveis nos estudos analisados.

\section{O formador de professores de Matemática}

O termo "formador" pode fazer referência a diferentes agentes, e uma primeira abordagem seria defini-lo como "toda pessoa que se dedica profissionalmente à formação em seus distintos níveis e modalidades" (Vaillant, 2003, p. 22). No âmbito educacional, Marcelo García (1999) destaca seis significados distintos para esse termo, dentre os quais destacamos "os profissionais da universidade que formam professores". Concentramos nossa análise nas pesquisas com resultados sobre esses profissionais. Essa escolha se fundamenta, principalmente, nas considerações sobre a lacuna de conhecimento a respeito do docente que atua na licenciatura (André et al., 2010; Fiorentini, 2004; Fiorentini et al., 2002; Marcelo

\footnotetext{
${ }^{3}$ Esse estudo também se insere na pesquisa de doutorado da primeira autora, realizada sob orientação da segunda, no Programa de Pós-Graduação em Educação da Universidade Federal de São Carlos.

${ }^{4}$ Projeto de pesquisa aprovado no Edital Chamada Universal; MCTI/CNPQ nº 014/2014, coordenado pelo Prof. Dr. Dario Fiorentini (FE/UNICAMP).

5 Para Romanowski e Ens (2006), os estudos realizados a partir de uma sistematização de dados, chamados estado da arte, recebem esta denominação quando abrangem toda uma área do conhecimento, nos diferentes aspectos que geraram produções. Assim, devem considerar toda publicação relativa ao tema, como artigos publicados em periódicos, anais de eventos científicos, dissertações, teses etc. O estudo que aborda apenas um setor das publicações sobre o tema estudado, como é nosso caso, que consideramos apenas dissertações e teses, segundo a autora, vem sendo denominado de estado do conhecimento.
} 
García, 1999; Vaillant, 2003), apesar de seu papel central na formação de professores (Altet, Paquay, \& Perrenoud, 2003; Santos, 2005; Zeichner, 2005). Utilizamos a palavra "formador" para designar todos os docentes da universidade que atuam na licenciatura, os professores das disciplinas de práticas de ensino e estágio supervisionado, os das disciplinas pedagógicas em geral, os das disciplinas específicas de diferentes áreas de conhecimento (Mizukami, 2005).

Consideramos que o formador é um elemento importante na formação docente, na medida em que, durante suas aulas, realiza um trabalho muito parecido com o que o licenciando presenciou quando aluno na Educação Básica e com o que pode realizar quando for lecionar. Por outro lado, o formador é, ele próprio, um professor que também se forma no exercício da profissão, pois precisa mobilizar seus conhecimentos para empreender práticas que atendam às demandas do seu contexto profissional. Desse modo, mantém uma dupla relação com a formação de professores: como agente em sua própria formação e na formação de seus alunos, futuros professores.

Esse docente é responsável pela formação do professor de Matemática, mesmo que não tenha essa intenção, pois nos cursos de Licenciatura em Matemática, nas disciplinas

de Cálculo, Análise ou Álgebra, o futuro professor não apenas aprende uma certa matemática, como é esperado pelo formador, mas aprende também um modo de estabelecer relação com o conhecimento; internaliza também um modo de concebê-lo, de tratá-lo e de avaliá-lo no processo de ensino e aprendizagem. (Oliveira \& Fiorentini, 2013, p. 926)

Neste estudo, devido à nossa trajetória de formação e de atuação profissional, voltamos o olhar para os resultados relativos ao docente que atua na Licenciatura em Matemática, que doravante será designado pelo termo "formador de professores de Matemática".

\section{A Constituição do corpus e os procedimentos de análise}

Com a intenção de conhecer a produção acadêmica brasileira sobre o formador de professores de Matemática, realizamos uma busca em duas etapas: tomando como ponto de partida o escopo do projeto nacional no qual se insere o presente estudo, acessamos os 858 fichamentos $\operatorname{produzidos}^{6}$ e, a partir da leitura de cada um, principalmente das partes dedicadas aos contextos e aos sujeitos, aos resultados e às conclusões, localizamos 119

\footnotetext{
${ }^{6}$ Os fichamentos foram elaborados na primeira etapa do referido projeto, quando os pesquisadores participantes preencheram uma ficha-formulário para cada relatório de pesquisa, tendo por base seu texto completo. Nesses fichamentos constam: 1) dados identificadores da pesquisa; 2) problemática de partida, objetivos e questão investigativa; 3) procedimentos metodológicos (tipo de pesquisa, processo de coleta de dados, contexto e sujeitos, material ou corpus de análise, procedimentos de análise); 4) resultados e conclusões relativos ao PEM; 5) principais referenciais teóricos relativos ao PEM e sua presença na análise e na produção de resultados e conclusões.
} 
investigações que têm o formador de professores de Matemática como sujeito de pesquisa e/ou que estudam algum aspecto relativo a ele ${ }^{7}$.

Como o foco deste estudo se direciona ao conhecimento produzido sobre o formador de professores de Matemática, acessamos o texto completo dessas 119 pesquisas, em busca de resultados relativos a esse docente. Nessa segunda etapa, por meio da leitura dos capítulos dedicados à apresentação dos resultados e/ou às análises e às considerações finais de cada estudo, identificamos 30 pesquisas (Anexo A) que produziram resultados a respeito da atuação, do pensamento, dos saberes, da formação, do desenvolvimento profissional ou da profissionalidade desse docente e que se constituíram no corpus de análise.

A análise dessa produção foi realizada a partir da leitura dos textos completos dos 30 trabalhos que, por sua natureza qualitativa, não têm a intenção de generalizar os resultados para outros indivíduos, locais ou situações além daqueles que foram estudados (Creswell, 2010). Considerando tratar-se de um texto sobre o estado do conhecimento de pesquisas de pós-graduação, procuramos trazer o referencial teórico à medida que a nossa análise foi sendo tecida. O processo analítico buscou indicar tendências, lacunas, mudanças de ênfase e reorientações para sistematizar o conhecimento, produzido nas teses e dissertações mapeadas, sobre o formador de professores de Matemática. Tal processo nos permitiu agrupar as pesquisas em duas temáticas, como apontamos na parte dedicada aos resultados.

\section{Tendências das pesquisas sobre o formador de professores de Matemática}

Tomando por referência os 858 trabalhos considerados no projeto nacional, os 30 trabalhos - 17 dissertações de mestrado acadêmico (MA), duas de mestrado profissional (MP) e 11 teses de doutorado (DO) - que compõem o corpus de análise representam 3,5\% da produção. Essa proporção é praticamente a mesma da observada por Fiorentini et al. (2002), que identificaram quatro trabalhos sobre a formação, o pensamento e a prática dos formadores de professores de Matemática (Brasil, 2001; Garnica, 2001; Gonçalves, 2000; Silva, 2001) dentre os 112 que compuseram o balanço dos 25 anos da pesquisa brasileira sobre a formação de professores que ensinam Matemática. Assim, como indicam Kothagen, Loughran e Lunenberg (2005), não se observa no Brasil a tendência internacional de crescimento nas investigações sobre o docente que atua na formação de professores.

Em relação às condições de produção, os 30 estudos foram desenvolvidos em programas de pós-graduação de 14 instituições de ensino superior distintas, dentre as quais PUC/SP, UFPA, ${ }^{8}$ Unesp de Rio Claro e Unicamp concentram mais da metade da produção 9 .

\footnotetext{
${ }^{7}$ As pesquisas identificadas não estão necessariamente associadas ao foco temático "Atuação, pensamento ou saberes do formador de PEM" da ficha-formulário pois alguns estudos produzem resultados a respeito do formador de professores de Matemática, ainda que o foco temático assinalado na ficha-resumo seja outro, como é o caso da pesquisa de Momade (2010).
} 
As orientações dessas pesquisas foram realizadas por 25 docentes diferentes, sendo que somente Laurizete F. Passos (PUC/SP), Dario Fiorentini (Unicamp) e Tadeu O. Gonçalves (UFPA), professores de três das quatro instituições que concentram a pesquisa sobre o formador de professores de Matemática, orientaram mais de um estudo.

Quanto ao processo investigativo, o problema está explícito em 26 trabalhos, e o memorial pessoal ou acadêmico foi a estratégia mais usada pelos autores para tratar a problemática até chegar à questão de pesquisa. Vinte e nove relatórios trazem pelo menos uma questão e 26 indicam objetivos. Predominaram as pesquisas de natureza empírica ou de campo, que são 27, e a abordagem metodológica qualitativa ocorreu em 28 trabalhos. Os tipos de pesquisa mais desenvolvidos foram o etnográfico ou participante e o estudo de caso, cada um em nove estudos. A respeito da produção de dados, predominam as pesquisas que combinam diferentes instrumentos, são 23, e os mais usados foram a entrevista, em 23 estudos, e o questionário, em 12.

Dos 30 estudos, o contexto em que se realizou a pesquisa foi definido em 28 trabalhos, dos quais participaram docentes de 39 instituições diferentes: uma universidade alemã, uma em Moçambique e as demais situadas em nove estados brasileiros. A maioria (23) foi realizada com a participação de formadores que atuavam em uma só instituição de ensino superior (IES). Há uma concentração de pesquisas cujos dados foram produzidos em IES do estado de São Paulo (37\%), o que também se observa em relação aos participantes das pesquisas pois, dos 229 formadores envolvidos nas investigações que analisamos, 68 (30\%) atuavam em cursos paulistas (Tabela 1).

Tabela 1 - Dados relativos aos contextos de produção dos dados

\begin{tabular}{c|c|c|c}
\hline $\begin{array}{c}\text { Local em que a pes quisa } \\
\text { foi realizada }\end{array}$ & $\begin{array}{c}\text { Número de pes quis as } \\
\text { realizadas }\end{array}$ & $\begin{array}{c}\text { Número de } \\
\text { ins tituiçoes em que } \\
\text { fram des envol vidas as } \\
\text { pesquis as }\end{array}$ & $\begin{array}{c}\text { Número de formadores } \\
\text { de profess ores } \\
\text { participantes das } \\
\text { pes quis as }\end{array}$ \\
\hline SP & 11 & 9 & 68 \\
PA & 5 & 3 & 35 \\
CE & 2 & 3 & 6 \\
GO & 2 & 2 & 9 \\
PR & 2 & 7 & 27 \\
AC & 1 & 1 & 35 \\
AL & 1 & 3 & 16 \\
MG & 1 & 8 & 3 \\
MT & 1 & 1 & 2 \\
Alemanha & 1 & 1 & $\mathbf{1 3}$ \\
Moçambique & 1 & 1 & $\mathbf{2 2 9}$ \\
Não menciona & 2 & - & \\
\hline TOTAL & $\mathbf{3 0}$ & & 39 \\
\hline
\end{tabular}

Fonte: Organização das autoras

Dentre os 229 participantes das pesquisas que consideramos, há informações sobre a formação acadêmica de 198 formadores. A maioria (60\%) é licenciada em Matemática, 137

\footnotetext{
${ }^{9}$ Número de trabalhos por instituição: PUC/SP (6), UFPA (4), Unicamp (3) e Unesp de Rio Claro (3), somando 16 pesquisas.
} 
(69\%) fizeram mestrado e $80(40 \%)$ doutorado. Quanto à área da pós-graduação, predominam o mestrado em Matemática (35\%) e em outras áreas (37\%) e o doutorado em Matemática (48\%). Esse perfil é semelhante ao dos coordenadores dos cursos de Licenciatura em Matemática $^{10}$, que fizeram principalmente graduação $(94,1 \%)$ e pós-graduação $(69,4 \%)$ na área de Ciências Exatas e da Terra (Brasil, 2015), e corrobora a afirmação de que os

investigadores-formadores que atuam na licenciatura em matemática são matemáticos ou cientistas de outras áreas - tais como Física, Psicologia, Filosofia e História da Educação, etc - que, de um lado, possuem conhecimento sólido em um dos campos científicos e procuram realizar estudos neste âmbito, mas, de outro, possuem pouca ou nenhuma formação didático-pedagógica (Fiorentini, 2004, p. 5).

Os 30 estudos que analisamos focalizaram majoritariamente o formador de professores que, embora licenciado, realizou seus estudos de pós-graduação na Matemática, perfil representativo do que se observa no Brasil e que denota uma formação acadêmica voltada para os conteúdos circunscritos à área de conhecimento da Matemática, com pouca interlocução com aspectos relacionados ao ensinar e ao aprender e com a formação de professores.

\section{As pesquisas sobre o formador de professores de Matemática e seus resultados}

A análise da produção considerada, feita a partir dos resultados que identificamos nos 30 estudos, revelou que essas pesquisas produziram conhecimentos sobre o que diziam, faziam, pensavam os formadores ou sobre a sua formação. Por isso, organizamos esses trabalhos em dois grupos temáticos: atuação ou pensamento do formador de professores de matemática, quando apresentam conclusões sobre as concepções ${ }^{11}$ dos formadores e/ou suas práticas pedagógicas, e formação, aprendizagem, desenvolvimento ou constituição profissional do formador de professores de matemática, quando as dissertações e teses trazem considerações sobre "processos de aprendizagem e desenvolvimento da construção do conhecimento e do desempenho profissional dos docentes" (Roldão, 2007, p. 53) que atuam na Licenciatura em Matemática. O Quadro 1 traz a distribuição das pesquisas segundo essas duas temáticas.

\footnotetext{
${ }^{10}$ Como a condição necessária para ser coordenador de um curso de graduação é ter sido professor do curso, consideramos que os coordenadores são formadores de professores. Diante da amplitude dos resultados produzidos no ENADE 2014, que se refere a todos os cursos de Licenciatura em Matemática do Brasil, utilizamos os dados do Perfil do coordenador (Brasil, 2015) como parâmetro de comparação para o perfil dos formadores que participaram das pesquisas que analisamos.

11 Quando usamos o termo "concepções", nos referimos ao construto de Thompson (1992), que compreende concepção como uma estrutura mental que abrange concepções, conceitos, significados, proposições, regras, imagens mentais, preferências e gostos.
} 
DOI: http://dx.doi.org/10.20396/zet.v25il.8647556

Quadro 1 - Distribuição dos trabalhos por temática ${ }^{12}$

\begin{tabular}{c|c|c|c}
\hline $\begin{array}{c}\text { Atuação, pensamento ou saberes do formador de } \\
\text { profess ores de mate mática }\end{array}$ & $\begin{array}{c}\text { Formação, aprendizagem, desenvolvimento ou } \\
\text { cons tituição profissional do formador de } \\
\text { professores de matemática }\end{array}$ \\
\hline ALONSO (2003) & MAGALHÃES (2010) & HARUNA (2004) & GOULART (2009) \\
CANOAS (2005) & MOMADE (2010) & BITENCOURT (2006) & PONTELLO (2009) \\
FERREIRA (2005) & CAVALCANTE (2011) & SOARES (2006) & SILVA (2009) \\
SANCHES (2006) & JANZEN (2011) & TRALDI JÚNIOR (2006) & MELO (2010) \\
SILVA (2007) & BELO (2012) & ROOS (2007) & SILVA (2010) \\
PINHEIRO (2008) & DIAS (2012) & COSARDI (2008) & FARIA (2012) \\
PAMPLONA (2009) & MARTINES (2012) & & \\
GOSMATTI (2010) & MARTINS (2012) & & \\
KOMATSU (2010) & & & \\
\hline & $\mathbf{1 7}$ & &
\end{tabular}

Fonte: Dados organizados pelas autoras

Atuação ou pensamento do formador de professores de matemática

Nessas 17 pesquisas, identificamos resultados sobre o que os formadores pensam a respeito das disciplinas História da Matemática (Ferreira, 2005; Silva, 2007) e Análise (Martines, 2012), do uso de diferentes mídias (Sanches, 2006; Momade, 2010; Dias, 2012), do estágio supervisionado (Gosmatti, 2010; Magalhães, 2010), sobre educação (Alonso, 2003), sobre seu trabalho (Canoas, 2005), sobre o ensino de matemática (Martins, 2012) e sobre a formação de professores (Belo, 2012). Outras (Pinheiro, 2008; Pamplona, 2009; Komatsu, 2010; Cavalcante, 2011; Janzen, 2011) se concentraram nas práticas dos formadores.

Alguns formadores reconhecem a importância das disciplinas que ministram para além da constituição do conhecimento matemático do futuro professor de Matemática, tendo em vista o "desenvolvimento do senso crítico e da maturidade matemática nos educandos, como também propiciar reflexão sobre a inserção cultural da evolução dos conceitos da Matemática na História da humanidade" (Ferreira, 2005, p. 106), no caso da História da Matemática; e o papel de fundamentar, consolidar e aprofundar o conhecimento matemático do futuro professor, reconhecendo a matemática escolar e suas especificidades no processo de formação (Martines, 2012), em relação ao conteúdo de Análise. Embora se observem docentes com "a percepção de que a formação do professor exige mais que um conhecimento matemático técnico-formal dos conteúdos" (Martines, 2012, p. 107), ainda se identificam relatos em que "os professores priorizam esgotar o ensino do conteúdo das disciplinas que ministram" (Silva, 2007, p. 110).

Em se tratando das diferentes mídias educacionais, os formadores que participaram da pesquisa de Sanchez (2006, p. 88) "têm a convicção de que o quadro é essencial para a construção, demonstração e transposição do conhecimento matemático, porém deixam transparecer como aprenderam a usar o quadro na prática e que no início usaram como seus

\footnotetext{
12 Os trabalhos escritos em negrito são teses de doutorado, os que estão em itálico, dissertações produzidas no âmbito de mestrados profissionais e os demais são dissertações de mestrado acadêmico.
} 
professores". Além disso, eles reconhecem que o quadro de escrever é necessário nas salas de aulas porque as novas tecnologias não estão à disposição do sistema educacional (Sanches, 2006). A respeito das tecnologias de informação e comunicação (TICs), a maioria dos professores depoentes de uma investigação acredita "que o uso das tecnologias nos cursos de formação pode causar mudanças em sua formação e nas práticas pedagógicas dos futuros professores, e demonstram interesse em aprender a melhor usar as TICs" (Momade, 2010, resumo). Nesse sentido, verificou-se que, na formação inicial dos professores, para o uso das TIC em um curso de Licenciatura em Matemática é enfatizado o poder da tecnologia de promover a qualidade da educação, como um fim em si mesmo, ou seja, as ferramentas tecnológicas são colocadas como uma solução instantânea de melhoria da educação (Dias, 2012). Os formadores que participam dessas investigações (Sanches, 2006; Momade, 2010; Dias, 2012), segundo identificamos, usam as mídias de forma tradicional, como foi o caso do quadro de escrever, e que as novas mídias são, por si sós, vistas como catalisadoras de mudança.

O estágio supervisionado é entendido pelos professores entrevistados na pesquisa de Gosmatti (2010, p. 35) como práxis, ou seja, como "atividade teórico-prática humana de transformação na natureza e da sociedade", como imitação de modelos, instrumentação técnica e como tempo em sala de aula - no sentido de estar na escola, em sala de aula. Percebemos que as expectativas dos formadores em relação aos graduandos e o entendimento da sua ação docente determinam a maneira como o estágio curricular será desenvolvido e que tipo de atividade será proposta nesse momento da formação inicial de professores de matemática. No trabalho de Magalhães (2010), a maior parte dos docentes responsáveis pela disciplina de estágio o considera em uma perspectiva tradicional, como o momento de aproximação e aprendizagem da docência. Além disso,

o discurso da maioria dos professores em relação à sua prática pedagógica, retrata uma perspectiva prática de reflexão, na qual os métodos científicos servem de parâmetros para a análise da prática. A prática dos professores não aborda uma relação dialética entre teoria e prática de forma que o processo de pesquisa sobre a prática ainda é incipiente. Outro aspecto que reflete esta perspectiva é a abordagem teórica que os professores fazem para fundamentar as discussões nas aulas de estágio e a abordagem teórica exigida nos relatórios. (Magalhães, 2010, p. 197)

Os resultados de oito pesquisas (Ferreira, 2005; Sanches, 2006; Silva, 2007; Dias, 2010; Gosmatti, 2010; Magalhães, 2010; Momade, 2010; e Martines, 2012) sobre o que os formadores de professores de Matemática pensam quanto às disciplinas que ministram, ao uso que fazem das mídias e ao estágio supervisionado apontam certa dificuldade desses docentes em romper com modelos nos quais eles próprios foram formados. Essa evidência corrobora a consideração de Martines (2012, p. 99) a respeito de uma "circunstância cíclica, na qual alguns docentes que ministram disciplinas específicas de matemática são bacharéis com pós-graduação na área de matemática e quando vão lecionar disciplinas na graduação acabam reproduzindo sua própria formação." 
Ainda no âmbito das pesquisas sobre as concepções dos formadores, dois estudos (Alonso, 2003; Canoas, 2005) apresentam os resultados similares. As precárias condições de trabalho do professor da Educação Básica são apontadas por Alonso (2003) como "insatisfações com a realidade em que vive o professor do Ensino Fundamental e Médio, principalmente na questão salarial, pela ausência da família na formação do adolescente e com o despreparo dos alunos para a aprendizagem matemática” (p. 80). Canoas (2005) identificou que os formadores têm consciência da precariedade do trabalho de professor e se sentem gratificados com a escolha da carreira no nível superior, pois "se colocam no comando de um projeto pedagógico próprio, com a finalidade de transmissão e produção de conhecimento, estímulo à geração de novas atitudes no aluno" (p. 116). Ele destaca também que a pesquisa desenvolvida por esses docentes em nível de pós-graduação parece estar desconectada da sua práxis e que eles reforçam sua experiência profissional no processo de formação de professores de Matemática.

Em alguns trabalhos, os docentes com formação específica em Matemática reforçavam nos licenciandos a ideia de que, para ser professor de Matemática, "basta dominar plenamente apenas o conteúdo que eles lhes oferecem em cada uma das disciplinas do curso" (Canoas, 2005, p. 115). Os formadores que participaram do estudo de Belo (2012) também "entendem que para formar um bom professor de matemática basta que estes saibam o conteúdo e saiba instrumentalizar a prática com metodologias adequadas” (pp. 139-140). Belo (2012) considera que tal concepção se deve à falta de clareza, por parte dos formadores, a respeito da formação docente e da especificidade de trabalhar com a formação de futuros professores de matemática para a educação básica, o que tornaria compreensível esperar que a maioria deles "reproduza as práticas de seus formadores, ou experiências que julgam adequadas para desenvolverem suas atividades" (pp. 139-140).

Em um dos estudos, mesmo que de forma incipiente e ainda associada aos modelos nos quais os formadores foram formados, observamos

uma tendência à superação de concepções ligadas aos modelos estáticos da matemática, embora suas concepções sejam fortemente caracterizadas por elementos ligados a uma matemática instrumental. Assim, ao mesmo tempo em que consideram pertinente a adoção de um modelo de ensino mais inovador, não entendem que o professor é o profissional que deve propor situações de ensino que favoreçam a aprendizagem, bem como, não entendem que o erro pode ser utilizado no ensino para potencializar a aprendizagem do aluno. (Martins, 2012, p. 107)

Esses resultados que destacamos nas pesquisas de Canoas (2005) e Martins (2012) confirmam as considerações de Belo (2012) e

parecem indicar que as identidades profissionais dos formadores como pesquisadores em matemática contribuem ... e influenciam na forma como esses formadores se percebem e desenvolvem suas tarefas no curso. Uma problemática a destacar é o (des) conhecimento da dimensão pedagógica do curso, em nosso entendimento, também resultante da ausência de formação pedagógica desses formadores. (Belo, 2012, p. 138) 
Essas investigações revelaram uma dificuldade do formador em conectar as pesquisas que desenvolve à sua prática (Canoas, 2005), embora sua compreensão sobre a formação de professores tenha sido influenciada por sua identidade profissional como pesquisador em Matemática. Trata-se de uma identidade marcada pelo desconhecimento da dimensão pedagógica do curso, o que resultaria da ausência de estudos nesse campo e o levaria a reproduzir as práticas de seus formadores ou as experiências que julga pertinentes para suas atividades (Belo, 2012). Assim, a identidade de pesquisador marca a prática do formador de professores de Matemática pela lacuna em sua formação pedagógica e pela distância entre a pesquisa que desenvolve e sua prática docente.

No âmbito das pesquisas que focalizaram a prática do formador na Licenciatura em Matemática, Pinheiro (2008) constatou que "a formação inicial do professor em Engenharia Civil influencia a sua prática pedagógica, na valorização da técnica de construção do desenho, em detrimento da demonstração matemática presente na produção de cada figura" (resumo). A autora considera outras influências da prática desse formador na formação dos licenciandos, quando destaca que,

em sala de aula, o professor sempre esteve voltado para desenvolver as competências do aluno no sentido de aprendizagem dos conteúdos, isto é, das construções geométricas. Não se percebeu a ação pedagógica do Professor observada no sentido de exploração desses conteúdos com os futuros alunos desses licenciados que estavam em formação. Podemos dizer que o aluno que cursou a disciplina Desenho Geométrico cresceu em relação à sua percepção geométrica, mas não no que é pertinente à transposição destes conteúdos para o ensino. (Pinheiro, 2008, p. 139)

Mesmo que essa pesquisa indique uma prática estritamente voltada para o conteúdo matemático, em que o objetivo maior do formador é que os alunos da Licenciatura em Matemática aprendam esses conteúdos, sem considerar que poderão vir a ensiná-lo, observamos resultados que não se limitam a essa lógica.

A pesquisa de Pamplona (2009) indica que os formadores questionam as práticas que relacionam as formações de conteúdo e pedagógica de forma desigual, ou seja, que valorizam uma dimensão da formação em detrimento da outra. Esses formadores compartilham com seus alunos outras práticas, em que procuram evidenciar e fortalecer os nexos entre essas duas dimensões da formação. Essas práticas foram:

o compartilhamento - com os licenciandos - dos problemas, das escolhas, dos trajetos, das perspectivas e dos prazeres que fazem parte do exercício da profissão do professor, de modo geral, e do ensino da Estatística, de modo particular; o questionamento das práticas discursivas e não discursivas que apoiam relações desiguais de poder entre práticas de formação matemática/estatística e práticas de formação pedagógica; entre outras. (Pamplona, 2009, resumo)

A pesquisa de Komatsu (2010) revelou que alguns formadores vincularam a pesquisa e a prática docente, valorizando as investigações que desenvolvem, devido à aquisição de conhecimentos, tanto de ordem pedagógica como de conteúdos da Matemática. Já o estudo de Cavalcante (2011) indica que formadores constituíram novos saberes a partir da ação, pela conceituação dos conteúdos matemáticos, seja "rompendo com o modelo exclusivamente 
teórico, tendo a formação realizada com situações práticas, que fazem a teoria surgir" (p. 113) ou mesmo adotando uma perspectiva de vivência com aulas simuladas, com um modelo predeterminado pelo formador e um "modelo aplicacionista de formação prevalecendo" (p. 113).

Tendo em vista o papel do professor de ensino superior como formador do pensar matematicamente (Janzen, 2011), tanto a autora quanto os formadores participantes consideram que "não basta o professor ter domínio do conteúdo matemático, ele precisa estar apto a guiar o aluno no processo de prova, e isto exige uma faceta de organizador: auxiliar o aluno a organizar suas ideias para que este chegue a uma prova como resultado" (p. 124).

A análise que realizamos dos resultados sobre o que pensam os formadores e sobre suas práticas denota que, embora alguns docentes mostrem certa dificuldade em romper com os modelos nos quais foram formados e expressem uma compreensão sobre a formação de professores marcada por suas identidades profissionais como pesquisadores em Matemática, suas práticas indicam algum movimento, ainda que tímido, no sentido de transpor a lógica de uma formação de professores voltada para o conhecimento estritamente matemático dos conteúdos.

Formação, aprendizagem, desenvolvimento ou constituição profissional do formador de professores de matemática

Esses 13 estudos produziram resultados sobre a formação do formador de professores de Matemática no que se refere à articulação de saberes com a prática docente (Haruna, 2004); à aprendizagem da docência no ensino superior (Bitencourt, 2006); à forma como constituem e elaboram seus saberes (Soares, 2006); às possibilidades de desenvolvimento profissional (Traldi Júnior, 2006); às ressignificações no fazer docente (Roos, 2007); à constituição profissional (Silva, 2009), a seu desenvolvimento profissional (Sicardi, 2008) e às especificidades de seu trabalho (Costa, 2009); a uma proposta de formação do formador (Goulart, 2009); aos percursos de formação (Pontello, 2009); ao modo como aprendem e transformam suas práticas e saberes (Melo, 2010); aos saberes e práticas a partir da atuação do formador na modalidade $\mathrm{EaD}$ (Silva, 2010); e à transição que vivenciaram com o trabalho (Faria, 2012).

Pela análise dessas pesquisas, foi possível identificar resultados sobre os saberes necessários para a atividade profissional do formador de professores de matemática e sobre como são constituídos ao longo de sua trajetória. Os autores desses estudos usaram predominantemente o arcabouço teórico de Maurice Tardif para designar o corpus de saberes/conhecimentos mobilizados pelo formador em sua prática docente e os meios pelos quais esses saberes se desenvolvem.

Para os formadores que participaram dessas investigações, os saberes disciplinares, estreitamente ligados ao conteúdo a ser ensinado, são condição fundamental para o exercício da docência, inclusive do formador de professores de Matemática (Sicardi, 2008). Tal clareza não se verifica em relação aos formadores da área específica da Matemática, quando se 
referem aos outros saberes docentes, na medida em que "com a atualização constante em conhecimentos ligados à Matemática, para o exercício da docência, [os formadores] percebem a necessidade dos conhecimentos disciplinares e não a existência de outros saberes/conhecimentos ligados à formação do futuro Professor de Matemática" (Haruna, 2004, resumo).

Conflitos e falta de valorização dos saberes pedagógicos foram observados entre os formadores da área específica da Matemática, que, embora indiquem que tais saberes são importantes, não apresentam em suas falas ações que confirmem essa valorização (Soares, 2006). É possível que isso decorra da constituição profissional - segundo Melo (2010), predominantemente técnico-científica - desses formadores e da constituição tardia de outros saberes requeridos para o campo de formação, "que envolve articulações entre saberes técnico-científicos, saberes pedagógicos e saberes experiências" (Melo, 2010, p. 264), que aconteceria a partir do engajamento e da efetiva participação no campo de formação durante o processo de atuação como professor formador.

Essa tendência de valorização dos saberes estritamente ligados ao conteúdo matemático diverge da observada entre os docentes com formação nas ciências da educação, que criticaram "as atitudes dos professores das disciplinas específicas com relação à não valorização das disciplinas pedagógicas e das ações pedagógicas" (Soares, 2006, p. 149) e indicaram haver necessidade de equilíbrio entre os saberes (Pontello, 2009). Esses docentes mostraram ter consciência de que ser formador é mais do que ensinar conceitos: envolve a "necessidade de dar mais ênfase, na formação de futuros professores de matemática, a conhecimentos que interligam aspectos cognitivos, conceituais, procedimentais e epistemológicos da matemática com aspectos didático-pedagógicos, sócio-culturais e práticos do ensino de matemática" (Roos, 2007, p. 93).

A formação acadêmica que, nas pesquisas analisadas, marca a divisão dos formadores de professores de Matemática em dois grandes grupos - matemáticos, quando a formação se deu na área das Ciências Exatas, e educadores matemáticos, formados nas áreas de Educação ou de Ensino - é reconhecida por esses docentes como "fundamental e constitui um diferencial no processo de constituição profissional" (Soares, 2006, resumo). As marcas dessa formação se fazem presentes na ação do formador, atingindo a formação de seus alunos, futuros professores de Matemática, pois, em função da área do formador, "seus discursos se dividem, valorizando, ou reconhecendo, cada um, o discurso compartilhado por seu grupo acadêmico" (Pontello, 2009, p. 97). Esses discursos "que os professores formadores fazem circular parecem produzir efeitos e verdades que ultrapassam os domínios da sua atuação e se disseminam no espaço acadêmico, constituindo também o olhar e as práticas dos alunos em processo de formação" (Melo, 2010, p. 2).

Os saberes experienciais e práticos foram indicados nas 13 pesquisas como centrais na constituição profissional do formador de professores de Matemática. Os resultados apontam que foram desenvolvidos em processos marcados por um "choque de realidade", pois é na prática pedagógica que os formadores aprendem a ser professores (Soares, 2006). O caminho 
de construção desses saberes necessários para a atuação dos formadores não foi único e, para trilhá-lo, os sujeitos significaram seus saberes de maneira distinta, conforme as oportunidades, as opções e as reflexões que fizeram no decorrer de sua profissão de professor, seja na educação básica ou no ensino superior (Bitencourt, 2006).

Para alguns formadores, a universidade foi o primeiro espaço de atividade docente, e a experiência como docentes na graduação foi tomada por eles como "estopim do movimento para a aprendizagem da docência" (Sicardi, 2008, p. 128). Os licenciandos foram indicados como responsáveis pela mobilização de saberes na constituição profissional dos formadores, pois teriam motivado os momentos em que esses "reconhecem a necessidade de alterar suas práticas em função de provocações e questionamentos ou mesmo pela dinâmica desencadeada em sala de aula" (Sicardi, 2008, p 129). A conclusão semelhante chegou Silva (2009), mencionando que é no enfrentamento dos desafios oriundos do trabalho com os alunos que os formadores mobilizam diferentes saberes, que emergem à medida que desenvolvem seu trabalho.

Em todos os estudos, a prática foi considerada como lugar de formação e de produção dos saberes necessários para o exercício profissional do formador de professores de Matemática. É na prática profissional que os formadores se valem dos saberes, para compreender as exigências de seu contexto profissional, adequar seu desempenho e aperfeiçoar suas condições de trabalho ao longo do caminho (Faria, 2012). Nesse âmbito, os saberes da experiência serviram de referência para modificações em suas práticas (Silva, 2010).

No percurso formativo do formador, a trajetória é uma componente importante, na qual o professor se constitui formador, em um processo contínuo, pessoal e situado, que depende do local onde está inserido (Costa, 2004), das experiências vivenciadas desde a graduação e das concepções sobre a docência e a matemática (Sicardi, 2008). Os resultados desses estudos reforçam que a construção dos saberes docentes do formador é um continuum de aprendizagens, feita por múltiplos caminhos, que dependem dos novos significados que dão à formação inicial em face da prática de sala de aula (Bitencourt, 2006).

A colaboração é vista como paradigma promissor de desenvolvimento profissional, pois possibilita ao formador reelaborar suas concepções de ensino, ampliando as oportunidades de sua formação inicial (Traldi Júnior, 2006). Assim também, a presença de professores de matemática, trabalhando junto com o formador, "configurou-se como condição essencial na busca de (re)significações de formadores de professores sobre formação docente em Matemática" (Roos, 2007, p. 108).

Esses resultados indicam que o formador de professores de Matemática, principalmente o que realizou sua formação acadêmica na área das Ciências Exatas, teve na universidade uma formação com orientação disciplinar e não profissional, ou seja, ele foi formado para ser pesquisador, para produzir conhecimento em sua área de pesquisa, e não para formar futuros professores. Como a maioria não teve formação para ser professor e 
muito menos para formá-lo, em síntese, a formação dos formadores para seu exercício profissional se deu predominantemente na prática, em serviço; seus modos de constituição profissional foram principalmente técnico-científicos, e os saberes para a formação aconteceram a partir de sua efetiva atuação nesse campo, como formador (Melo, 2010).

\section{Algumas considerações}

Procuramos descrever as pesquisas que geraram resultados sobre concepções, práticas ou formação do docente que atua na Licenciatura em Matemática. Os 30 estudos que identificamos - 17 dissertações de mestrado acadêmico, 2 de mestrado profissional e 11 teses - representam 3,5\% da produção considerada no mapeamento nacional, proporção praticamente igual à observada em Fiorentini et al. (2002), o que indica que, no Brasil, a pesquisa sobre o formador de professores de Matemática permanece com reduzido número de trabalhos, como também constataram Nacarato et al. (2016).

Essas pesquisas foram orientadas por 25 docentes em 14 diferentes instituições de ensino superior. São predominantemente de natureza empírica, com abordagem qualitativa, dos tipos etnográfica ou de estudo de caso e se valem da entrevista e do uso de questionários para produzir dados. A maioria dos formadores participantes era licenciada em matemática com estudos de pós-graduação na área de matemática.

As 17 pesquisas associadas à temática atuação, pensamento ou saberes do formador de professores de Matemática trazem resultados sobre as implicações dessas concepções, práticas e saberes na formação de professores de Matemática. Essa ênfase reforça o papel central do docente universitário que atua na licenciatura na formação do futuro professor, mesmo que o formador não tenha conhecimento disso. Nos resultados desses estudos, identificamos certa dificuldade dos formadores de, em seu fazer docente, romper com modelos nos quais eles próprios foram formados. Talvez isso se deva, pelo menos em parte, a outra constatação dessas investigações: a de que a identidade de pesquisador marca a prática do formador, principalmente pela lacuna em sua formação pedagógica e pela distância entre a pesquisa que desenvolve e sua prática. Apesar disso, as dissertações e teses que se concentraram nas práticas de formadores de professores de Matemática mostraram um movimento desses formadores para transpor a reprodução das vivências que experimentaram em sua formação e avançar no sentido de considerar a complexidade do trabalho do professor que estão formando.

A temática formação, aprendizagem, desenvolvimento ou constituição profissional do formador de professores de matemática aglutina 13 estudos que mostraram o saber docente do formador de professores de Matemática na perspectiva indicada por Tardif (2002): um saber plural, composto por saberes de diferentes tipos, marcado pela valorização do conteúdo disciplinar e pela lacuna da formação pedagógica. Um saber desenvolvido na prática para atender às demandas do contexto profissional. Os resultados desses estudos denotam a dupla relação que o formador mantém com a formação de professores: ao ensinar conteúdos matemáticos, ensina um modo de ser professor e, nesse Zetetiké, Campinas, SP, v.25, n1, jan./abr.2017, p.7-26 
processo, também se forma, pois precisa mobilizar saberes para empreender práticas que atendam às demandas do seu contexto profissional.

Segue válida a consideração de que não basta ao formador conhecer os conteúdos, é preciso auxiliar os professores a ensinarem. Isso quer dizer que necessitam ter um suporte para transformar seus conhecimentos de conteúdos específicos em conhecimentos que possam ser apreendidos pelo grupo de alunos. E, no caso dos formadores, a definição da base de conhecimento é complexa, pois envolve um caráter duplo: o conhecimento necessário para ensinar os alunos de seus alunos, estes futuros professores, e o conhecimento referente à formação de professores (Dal-Forno \& Reali, 2009).

Os resultados dos estudos que constituem nosso corpus reforçam que os saberes são constituídos e constitutivos da prática docente do formador, pois dominá-los, integrá-los e mobilizá-los seriam condições para realizá-la (Tardif, 2002). Contudo, permanece válida a consideração de que a

\begin{abstract}
formação de formadores é um território pouco explicado e menos explorado ainda, cujos espaços para reflexão praticamente inexistem na bibliografia pedagógica e nos diversos cenários educativos, públicos e privados. Ocorre com este tema o mesmo que ocorre com o ensino: a crença de que o único que se requer para ensinar é o conhecimento do se ensina - o conteúdo ou matéria a ser ensinado. (Vaillant, 2003, p. 28)
\end{abstract}

Embora essas pesquisas tenham analisado a formação do formador de professores de Matemática, produzindo resultados sobre esse processo, é possível avançar na direção de delimitar saberes, conhecimentos específicos do formador, necessários à sua atividade profissional; e, ainda, analisar em que medida se diferenciam dos saberes do professor que ele forma. Consideramos, portanto, a necessidade de pesquisas que tomem como objeto de investigação os conhecimentos de que o formador necessita para seu exercício profissional, principalmente para formar professores de Matemática, rompendo os silêncios que prevalecem nas licenciaturas em Matemática.

\title{
Referências
}

Altet, M., Paquay, L., \& Perrenoud, P. (2003). A profissionalização dos formadores de professores. Porto Alegre: Artmed.

André, M. E. D. A., Almeida, C. A. A., Hobold, M. S., Ambrosetti, N. B., Passos, L. F., \& Manrique, A. L. (2010). O trabalho docente do professor formador no contexto atual das reformas e das mudanças no mundo contemporâneo. Revista Brasileira de Estudos Pedagógicos, 91(227), 122-143. Retirado em 07 de junho de 2013, de http://rbep.inep.gov.br/index.php/rbep/article/view/606/587.

Brasil. Ministério da Educação. Instituto Nacional de Estudos e Pesquisas Educacionais Anísio Teixeira. (2015). ENADE 2014 - Relatório de Área: Matemática. Brasília: MEC/Inep. Retirado em 25 de maio de 2016, de http://portal.inep.gov.br/enade/relatorio-sintese-2014. Brasil, V. R. A. (2001). As concepções e crenças dos professores de matemática da URCamp sobre "formar 
professores de matemática". Dissertação de Mestrado em Educação, Pontifícia Universidade Católica do Rio Grande do Sul, Porto Alegre.

Creswell, J. W. (2010). Projeto de pesquisa: métodos qualitativo, quantitativo e misto (3a ed.). Porto Alegre: Artmed.

Dal-Forno, J. P., \& Reali, A. M. M. R. (2009). Formação de formadores: delineando um programa de desenvolvimento profissional da docência via internet. Revista Profissão Docente, 9(20), 75-99. Retirado em 27 de maio de 2015http://www.revistas.uniube.br/index.php/rpd/article/view/236

Fiorentini, D. (2004). A investigação em Educação Matemática sob a perspectiva dos formadores de professores. In Anais do XV Seminário de Investigação em Educação Matemática (pp.)13-35, Covilhã: APM.

Fiorentini, D., Nacarato, A. M., Ferreira, A. C., Lopes, C. S., Freitas, M. T. M., \& Miskulin, R. G. S. (2002). Formação de professores que ensinam Matemática: um balanço de 25 anos da pesquisa brasileira. Educação em Revista, 36, 137-160.

Garnica, A. V. M. (1995). Fascínio da técnica, declínio da crítica: um estudo sobre a prova rigorosa na formação do professor de matemática. Tese de doutoramento em Educação Matemática, Universidade Estadual Paulista "Júlio de Mesquista Filho", Rio Claro.

Gonçalves, T. O. (2000). Formação e desenvolvimento profissional de formadores de professores: o caso dos professores de matemática da UFPA. Tese de doutorado em Educação Matemática, Faculdade de Educação, Universidade estadual de CampinasUnicamp,. Campinas.. Retirado em 07 de julho de 2013, de http://www.bibliotecadigital.unicamp.br/document/?code $=$ vtls000195854\&fd=y.

Kothagen, F., Loughran, J., \& Lunenberg, M. (2005). Teaching teachers: studies into the expertise of teacher educators: an introduction to this theme issue. Teacher and Teacher Education, 21(2), 107-115. Retirado em 13 de junho de 2016, de http://www.sciencedirect.com/science/article/pii/S0742051X0400126X

Marcelo García, C. (1999). La formación de los formadores como espacio de trabajo e investigación: dos ejemplos. XXI Revista de Educación, 1, 33-57. Retirado em 18 de janeiro de 2016, de http://www.redescepalcala.org/inspector/DOCUMENTOS\%20Y\%20LIBROS/FORMACION/Formado res.pdf.

Mizukami, M. G. N. (2005). Aprendizagem da docência: professores formadores. In J. Romanowski, P. L. Martins, \& S. R. A. Junqueira. Conhecimento local e conhecimento universal: formação docente, aprendizado e ensino (pp. 69-80). Curitiba: Editora Universitária Champagnat.

Nacarato, A. M., Passos, C. L. B., Cristóvão, E. M., Megid, M. A. B. A. \& Coelho, M. A. V. M. P. (2016). Tendências das pesquisas brasileiras que têm o professor que ensina matemática como campo de estudo: uma síntese dos mapeamentos regionais. In: D. Fiorentini, C. L. B. Passos, \& R. C. R. Lima (2016). Mapeamento da pesquisa acadêmica brasileira sobre o professor que ensina Matemática: período $2001-2012$. FE-Unicamp: Campinas. Retirado em 08 de março de 2017, de 
DOI: http://dx.doi.org/10.20396/zet.v25il.8647556

https://www.fe.unicamp.br/pf-fe/pf/subportais/biblioteca/fev-2017/e-bookmapeamento-pesquisa-pem.pdf.

Oliveira, A. T. C. C., \& Fiorentini, D. (2013). O lugar das matemáticas na licenciatura em matemática: que matemáticas, que práticas formativas? Bolema. Boletim de Educação Matemática, 27, 917-938. Retirado em 12 de março de 2014, de file:///C:/Users/Fl\%C3\%A1via/Downloads/8286-43636-1-PB.pdf

Roldão, M. C. (2007). A formação de professores como objeto de pesquisa - contributos para a construção do campo de estudo a partir de pesquisas portuguesas. Revista Eletrônica de Educação, 1(1), 50-118. Retirado em 15 de abril de 2015, de http://www.reveduc.ufscar.br.

Romanowski, J. P., \& Ens, R. T. (2006). As pesquisas denominadas do tipo "Estado da Arte" em Educação. Revista Diálogo Educacional, 6(19). Retirado em 12 de abril de 2016, de http://redalyc.uaemex.mx/src/inicio/ArtPdfRed.jsp?iCve=189116275004.

Santos, V. M. (2005). A formação de formadores: que formação é essa?. Revista de Educação PUC-Campinas, 18, 61-64. Retirado em 12 de abril de 2106, de http://periodicos.puccampinas.edu.br/seer/index.php/reveducacao/article/viewFile/260/243.

Silva, M. T. (2001). Relação entre formação e prática pedagógica de matemática do professor do curso de magistério das séries iniciais do ensino fundamental. Dissertação de Mestrado em Educação, Universidade Federal de Pernambuco, Recife.

Tardif, M. (2002). Saberes docentes e formação profissional. Petrópolis: Vozes.

Thompson, A. G. (1992). Teachers' beliefs and conceptions: a synthesis of the research. In D. A. Grouws, Handbook of research on Mathematics teaching and learning., (pp. 127- 146). New York: Macmillan Publishing Company.

Vaillant, D. (2003). Formación de formadores. Estado de la práctica. Buenos Aires: Preal, 2002. Retirado em 13 de novembro de 2015, de http://www.oei.es/docentes/articulos/formacion_formadores_estado_practica_vaillant portugues.pdf.

Zeichner, K. (2005). Becoming a teacher educator: a personal perspective. Teaching and Teacher Education, 21 (2), p. 117-124. Retirado em 30 de junho de 2015, de http://www.sciencedirect.com/science/article/pii/S0742051X04001234

\section{APÊNDICE 1: Relação das dissertações e teses do corpus de análise deste estudo}

Alonso, R (2003). O projeto pedagógico de um curso de Licenciatura em Matemática: avanços e perspectivas diante das pesquisas educacionais e das exigências legais. Dissertação de Mestrado em Educação. Campinas: Pontifícia Universidade Católica de Campinas.

Belo, E. S. V. (2012). Professores formadores de professores de matemática. Dissertação de Mestrado em Educação. Belém: Universidade Federal do Pará. Acesso em 20 de março de 2015. Bitencourt, L. P. (2006). Aprendizagem da docência do professor 
formador de educadores matemáticos. Dissertação de Mestrado em Educação. Cuiabá: Universidade Federal de Mato Grosso. Canôas, S. S. (2005). Perspectivas para a formação de professores de Matemática de uma Faculdade Isolada: modernização ou transformação? (1996-2002). Tese de Doutorado em Educação Matemática. Rio Claro, Universidade Estadual Paulista - Campus Rio Claro.

Cavalcante, N. I. S. (2011). Formação inicial do professor de matemática: a (in)visibilidade dos sabres docentes. Dissertação de Mestrado Profissional em Ensino de Ciências e Matemática. Campina Grande: Universidade Estadual da Paraíba.

Costa, V. G. (2009). Professores formadores dos cursos de Licenciatura em Matemática do estado de Minas Gerais. Tese de Doutorado em Educação Matemática. São Paulo: Pontifícia Universidade Católica de São Paulo. Dias, D. R. S. C. (2012). Usos das TIC por professores do Curso de Licenciatura em Matemática da PUC-Goiás. Dissertação de Mestrado em Educação. Goiânia: Pontifícia Universidade Católica de Goiás.

Faria, E. C. (2012). Do ensino presencial ao ensino a distância: a inovação na prática pedagógica de professores de Matemática. Tese de Doutorado em Educação Matemática. São Paulo: Pontifícia Universidade Católica de São Paulo.

Ferreira, T. F. (2005). A disciplina História da Matemática: Um estudo sobre as concepções do professor do Ensino Superior. Dissertação de Mestrado Profissional em Ensino de Matemática. São Paulo: Pontifícia Universidade Católica de São Paulo.

Gosmatti, S. (2010). Prática de Ensino na Perspectiva de Professores de Estágio Curricular Supervisionado de Matemática. Dissertação de Mestrado em Educação). Curitiba: Universidade Federal do Paraná.

Goulart, M. B. (2009). A formação de formadores e a integração do computador na licenciatura de matemática. Tese de Doutorado em Educação. Curitiba: Universidade Federal do Paraná.

Haruna, L. H. (2004). Visões dos formadores da Licenciatura em Matemática na construção dos saberes docentes. Dissertação de Mestrado em Educação Matemática. Rio Claro: Universidade Estadual Paulista - Campus Rio Claro

Janzen, E. A. (2011). O papel do professor na formação do pensamento matemático de estudantes durante a construção de provas em um ambiente de geometria dinâmica. Tese de Doutorado em Educação. Curitiba: Universidade Federal do Paraná.

Komatsu, M. Y. (2010). A pesquisa na prática docente de professores formadores: um estudo em um curso de Licenciatura em Matemática. Dissertação de Mestrado em Educação Matemática. São Paulo: Pontifícia Universidade Católica de São Paulo.

Magalhães, A. P. A. S. (2010). A Prática reflexiva no estágio supervisionado dos cursos de formação de professores de Matemática da Universidade Estadual de Goiás (UEG). Dissertação de Mestrado em Educação em Ciências e Matemática). Goiânia: Universidade Federal de Goiás.

Martines, P. T (2012). O papel da disciplina de análise segundo professores $e$ coordenadores. Dissertação de Mestrado em Educação Matemática. Rio Claro: Universidade Estadual Paulista Campus Rio Claro. 
Martins, R. L. (2012). Concepções sobre a matemática e seu ensino na perspectiva de professores que ensinam matemática em licenciaturas de Alagoas. Dissertação de Mestrado em Educação Matemática e Tecnológica). Recife: Centro de Educação, Universidade Federal de Pernambuco.

Melo, J. R. (2010). A formação do formador de professores de Matemática no contexto das mudanças curriculares. Tese de Doutorado em Educação. Campinas: Universidade Estadual de Campinas.

Momade, S. I. (2010). O uso das tecnologias de informação e comunicação pelos professores de matemática da Universidade Pedagógica de Moçambique - Delegação de Nampula. Dissertação de Mestrado em Educação em Ciências e Matemática. Goiânia: Universidade Federal de Goiás.

Pamplona, A. S. (2009). A formação estatística e pedagógica do professor de Matemática em comunidades de prática. Tese de Doutorado em Educação. Campinas: Universidade Estadual de Campinas.

Pinheiro, A. C. M. (2008). A mediação docente na construção do raciocínio geométrico de alunos da licenciatura em matemática na disciplina desenho geométrico. Dissertação de Mestrado em Educação. Fortaleza: Universidade Estadual do Ceará.

Pontello, L. S. (2009). Cartografia das relações de saber/poder, na formação de professores de matemática, nas universidades públicas de Fortaleza. Dissertação de Mestrado em Educação). Fortaleza: Universidade Estadual do Ceará.

Roos, L. T. W. (2007). (Re)Significações de formadores de professores sobre formação docente em Matemática. Tese de Doutorado em Educação. Piracicaba: Universidade Metodista de Piracicaba (UNIMEP).

Sanches, A. C. M. (2006). A matemática, o quadro de escrever e os formadores de professores de matemática: interpretando relações. Dissertação de Mestrado em Educação em Ciências e Matemáticas.

Sicardi, B. C. M. (2008). Biografias educativas e o processo de constituição profissional de formadores de professores de Matemática. Tese de Doutorado em Educação. Campinas: Universidade Estadual de Campinas.

Silva, J. R. A. (2010). CampusNet Amazônia: saberes e práticas docentes no curso de Matemática a distância da UEPA. Tese de Doutorado em Educação. Rio de Janeiro: Pontifícia Universidade Católica do Rio de Janeiro.

Silva, J. A. (2007). As concepções de professores formadores em relação ao uso da história da Matemática no processo ensino aprendizagem nos cursos de licenciatura em Matemática. Dissertação de Mestrado em Educação em Ciências e Matemáticas. Belém: Universidade Federal do Pará.

Silva, S. R. L. S. (2009). Os professores formadores do curso de Licenciatura em Matemática: condições da docência. Dissertação de Mestrado em Educação Matemática. São Paulo: Pontifícia Universidade Católica de São Paulo.

Soares, N. N. (2006). Constituição dos saberes docentes de formadores de professores de matemática. Dissertação de Mestrado em Educação em Ciências e Matemáticas. Belém: Universidade Federal do Pará. 
DOI: http://dx.doi.org/10.20396/zet.v25i1.8647556

Traldi Júnior, A. (2006). Formação de formadores de professores de Matemática: Identificação de possibilidades e limites da estratégia de organização de grupos colaborativos. Tese de Doutorado em Educação Matemática. São Paulo: Pontifícia Universidade Católica de São Paulo. 